\title{
OCULAR MICROBES AMONG DIABETICS ATTENDING FEDERAL MEDICAL CENTRE EBUTE METTA, LAGOS.
}

\author{
${ }^{1}$ Isiakpu, S.N. \\ Department of Ophthalmology, Federal Medical Centre, Ebute Metta, Lagos Nigeria \\ Email: drsmileforever1@gmail.com \\ ${ }^{2}$ Dr Ukwuoma, G.A. \\ Excel Eyecare Centre,\#7 Makurdi Road Otukpo, Benue State. \\ E-mail: bishoguk@gmail.com
}

${ }^{3}$ Okpo, Eme

Department of Optometry, Bayaro University Kano/ Department of Ophthalmology, Aminu Kano Teaching Hospital, Kano, Nigeria Email: doctorokpo@yahoo.co.uk

\section{${ }^{4}$ Okpo, N.O.}

Department of Food Technology, Federal College of Agricultural Produce Technology Kano, Nigeria.E-mail: elendungozi@yahoo.com

Corresponding author: drsmileforever1@gmail.com

DOI: $10.31364 /$ SCIRJ/v8.i10.2020.P1020818

http://dx.doi.org/10.31364/SCIRJ/v8.i10.2020.P1020818

\begin{abstract}
Diabetes mellitus is a major public health problem and one of the leading causes of morbidity and mortality worldwide. Ocular complications of diabetes affect every part of the eye, as well as visual functions. The infections of the external eye account for a significant percentage of ocular inflammation, some of which lead to visual loss as a result of corneal involvement. The purpose of this study was to ascertain the Ocular Microbes among Diabetics attending Federal Medical Centre Ebute Metta, Lagos State. The study was a clinic based prospective study carried out on 105 participants. Ocular examinations of the external and internal structures of the participants were performed. Visual acuity was taken using Snellens Visual Acuity Chart. Sterile Cotton Tipped swab was used to swab the conjunctiva and cul-de-sac of each participant. Gram Stain of the isolates from the culture was done to characterize and classify the isolated microbes. Presumptive isolates were stored on slants and biochemical tests were carried out on them for further characterization and identification. The major eye infections among the participants in this study comprised of conjunctivitis $21(38.18 \%)$ and stye $12(21.82 \%)$ in the experimental group and 24(48.2\%) and 12(24.0\%) in the control group respectively. Staphylococcus aureus [experimental 31 (56.4\%) and control groups 28 (56.0\%)] was the most ocular microbes isolated followed by Streptococcus pyogenes [experimental $11(20.0 \%)$ and control groups 14 (28.0)]. There is no significant relationship between common ocular microbes and eye infections in diabetics in this study. This is shown in the correlation $r=-0.013$ at 0.927 level of significance which is greater than $0.05(r=-0.03$ at 0.927, $\mathrm{P}>0.05$ ). Ocular microbes in diabetics with eye infections are the same in diabetics without eye infections. Most ocular infections can be caused by the normal flora of the eyes when host immunity is compromised. Hyperglycemia do not predispose diabetics to ocular infections.
\end{abstract}

Key Words: Diabetes mellitus, ocular infections, ocular microbes, Hyperglycemia

\section{INTRODUCTION:}

Diabetes Mellitus (DM) is a chronic disorder characterized by impaired glucose metabolism due to insulin deficiency

WWW.scirj.org

(C) 2020, Scientific Research Journal

http://dx.doi.org/10.31364/SCIRJ/v8.i10.2020.P1020818

This publication is licensed under Creative Commons Attribution CC BY. 
or its resistance, leading to hyperglycemia and subsequent development of vascular and neurological complications ${ }^{1}$. Diabetes is said to be present when there is the presence of hyperglycemia, usually after two separate tests. ${ }^{2}$ Generally, there are two types of diabetes mellitus namely: type 1, which is primarily caused by autoimmune pancreatic B cells destruction and is characterized by absolute insulin deficiency and type 2 , which is characterized by insulin resistance and relative insulin deficiency. ${ }^{3}$

Diabetes mellitus is a major public health problem and one of the leading causes of morbidity and mortality worldwide. $^{4}$ As in the chronic diseases, complications of diabetes mellitus affects all parts of the human body. These complications include nephropathy, cardiovascular diseases, neuropathy and eye damage. ${ }^{5}$ Infections are frequent in patients with diabetes mellitus. ${ }^{6}$ This is caused by the hyperglycemic environment which favors immune dysfunction (e.g damage to the neutrophil function, depression of the antioxidant system, and humoral immunity), micro-and macro-angiopathies, neuropathy, decrease in the antibacterial activity of urine, gastrointestinal and urinary dysmotility, and greater number of medical interventions in diabetes. ${ }^{7}$

With regard to the eye, diabetes mellitus may cause alteration in the retinal microvasculature, leading to diabetic retinopathy, and if unchecked retinopathy may lead to blindness. ${ }^{8}$ Other than the retinopathy, ocular complications of diabetes mellitus may include cranial nerve palsies, decreased corneal sensitivity, cataract, retinal ischemia, hemorrhagia, fluctuating refractive changes and ocular infections. ${ }^{9}$ Patients with diabetes mellitus have infections more often than those without diabetes mellitus due to defects in immunity. ${ }^{10}$

Diabetes mellitus is a major public health challenge in Nigeria. New diagnosis of diabetes mellitus is being made every day in health facilities across the country. The prevalence of diabetes in Nigeria is 3.0\%. ${ }^{11,12}$ Ocular complications of diabetes affect every part of the eye, as well as visual functions.

Eye infections are high in people with diabetes, infections of the eyelids, conjunctiva, corneal surface and infections keratitis occur frequently in people with diabetes mellitus, with conjunctivitis having the highest incidence. ${ }^{13,14}$

Studies on common pathogenic ocular microbes in diabetics are very scarce in Nigeria. A study conducted on ocular health status of diabetes mellitus patients in Uyo, South-South, Nigeria, showed diabetics have ocular infections such as corneal ulcers. $^{15}$

Diabetics are usually predisposed to microbial infections. This has been linked to defective immunity. The infections of the external eye account for a significant percentage of ocular inflammation, some of which lead to visual loss as a result of corneal involvement. However there is still lack of clinical evidence linking diabetes mellitus to ocular microbial infections in Lagos State, Nigeria. This lack of clinical evidence linking diabetes mellitus and ocular microbial infections informed the purpose of this study.

\section{METHODOLOGY}

The study was a clinic based prospective study conducted at the Ophthalmology and Medical Laboratory Departments of the Federal Medical Centre Ebute Metta, Lagos, Nigeria. Ebute-Metta is in Lagos Mainland Local Government Area in Lagos State. It lies between Latitude $6^{0} 28^{1} 45.9^{11}$ North and Longitude $3^{0} 22^{1} 22.5^{11}$ East. The study size of this research was 105 participants comprising of 55 experimental subjects (diabetics with eye infection) and 50 control subjects (diabetics without eye infection).

Participant included were Nigerians aged between 20 and 65 years of age (This age range was chosen to reduce the influence of growth and age on the research result). Experimental participants were diabetic patients who were diagnosed based on a fasting blood glucose concentration of $\geq 126 \mathrm{mg} / \mathrm{dl}$, or random blood glucose concentration of $\geq 200 \mathrm{mg} / \mathrm{dl}$ or glycated hemoglobin of $\geq 6.5 \%$ ( $48 \mathrm{mmol} / \mathrm{mol})$ on two separate tests. Participants excluded were Alcoholics, Smokers, Drug Addicts, Subjects who have HIV/AIDS, Hypertensives, Immuno compromised subjects and People on immunosuppressive drugs.

The estimated minimum sample size for this study was calculated based on the highest prevalence of diabetes in Nigeria which is about $28 \% .{ }^{11}$ Using Fisher's formula for sample size

$$
\mathrm{n}=\begin{gathered}
Z^{2} p q \\
d^{2}
\end{gathered}
$$

Where $\mathrm{n}=$ estimated sample size 
$\mathrm{z}=1.96$ critical value at $95 \%$ confidence level

$\mathrm{p}=$ percentage picking a choice and in this case having diabetes $(1-\mathrm{p}=1-0.03)$

$\mathrm{d}=$ error margin or confidence interval

$$
\begin{aligned}
& \mathrm{n}=(1.96)^{2} \frac{\times 0.03 \times(1-0.3)}{0.05^{2}} \\
& \mathrm{n}=3.84 \times \frac{0.03 \times 0.97}{0.0025}=44.6=45
\end{aligned}
$$

www.scirj.org

(C) 2020, Scientific Research Journal 
A total of 105 participants were selected for inclusion in this study. They were separated into two groups comprising 55 participants who were diabetic with eye infection (experimental group) and 50 participants who were diabetic without eye infection (control group).

\section{DATA COLLECTION}

The study was a clinic based prospective study; hence data collection involved direct collection of biologic material from participants. A detailed medical history (health and ocular) was taken per participant, which included family health history, present illness, social history and drug history. Visual acuity at far and near was taken using Snellens Visual Acuity Chart.

The blood pressure was taken using the left arm only while the patient was seated for at least 5 minutes before records were taken with both manual (U-mec) sphygmomanometer and digital blood pressure apparatus (double $\mathrm{G}$ ) and average of the two results taken. Fasting blood sugar of subjects after they had fasted for at least 12 hours (overnight) were determined using a glucometer (Accucheck Advantage, Roche Diagnostics, Mannhein, Germany). The eyes of the subjects were examined with the Slit Lamp (Haag - Streit Slit Lamp BM900, Haag - Streit Diagnostics, USA).

\section{Isolation of Ocular Microbes}

Sterile Cotton Tipped swab was used to swab the conjunctiva and cul-de-sac of each participant. The cotton tipped swab were capped immediately (observing all precautionary measures to avoid contamination) and taken to the Medical Laboratory for culture and identification. Culture media used were blood agar, chocolate agar, MacConkeys agar, Bruceilla blood agar. The culture media were incubated at $37^{\circ} \mathrm{C}$ aerobically for MacConkey agar plates while chocolate agar was incubated in $10 \% \mathrm{CO}_{2}$ atmosphere at $37^{\circ} \mathrm{C}$ overnight.

Gram Stain of the isolates from the culture was done to characterize and classify the isolated microbes. Presumptive isolates were stored on slants and biochemical tests were carried out on them for further characterization and identification.

\section{Biochemical Characterization and Identification of Isolates}

Biochemical tests were conducted to identify the different bacteria.

The biochemical tests conducted were:

a. Catalase test: A few drops of 3\% hydrogen peroxide was dropped to each culture and the culture was observed for oxygen bubble, which indicated a positive catalase test.

b. Bacitracin test: An inoculating loop was used to streak two or three colonies of a pure culture onto a blood agar plate. Heated forceps were used to place a bacitracin disk in the area of heaviest growth. This was incubated for 20 hours at $35^{\circ} \mathrm{C}$ in ambient air. Any zone of inhibition around the disk shows a sensitive test.

c. Coagulase test: Several isolated colonies of test organism were emulsified in $1 \mathrm{ml}$ diluted rabbit plasma in small tube to give a milky suspension. It was then incubated

d. at $35^{\circ} \mathrm{C}$ in ambient air for 4 hours and was examined at 1,2 and 4 hours for cloth formation by tilting the tube through $90^{\circ}$. Clot formation indicated a positive test.

e. Oxidase test: A filter paper soaked with tetramethyl-p- phenylenediaminedihydrochloride was moistened with sterile distilled water. The colony to be tested was picked with platinum loop and smeared in the filter paper and then observed for a deep blue or purple colour change within 10 - 30 seconds. A colour change signified a positive oxidase test.

f. Hemolysis test: A beta-lysin-producing strain of Staphylococcus aureus was streaked down the centre of a sheep blood agar plate to about 3 to $4 \mathrm{~cm}$ long. Test organisms were then streaked across the plate perpendicular to the Staphylococcusaureus streak within $2 \mathrm{~mm}$. It was incubated at $35^{\circ} \mathrm{C}-37^{\circ} \mathrm{C}$ in ambient air for 20 hours. Streptococci enhanced the $\beta$-lysin activity of the aureus strain, which indicated a positive test.

\section{Statistical Analysis}

Descriptive statistics and frequency counts were done on data generated and the results reported as means \pm standard deviations and percentages respectively. ANOVA and Pearson's correlation analysis were used to test the hypothesis raised in the study.

$$
\text { www.scirj.org }
$$

(C) 2020, Scientific Research Journal 
Level of significance was fixed at

0.05 and 0.01 . Pearson's correlation coefficients were calculated to assess the correlation between diabetes and common ocular microbes. Differences between group means were separated using one way analysis of variance (ANOVA), with the significant threshold fixed at $\mathrm{P}<0.05$.

Data analysis was carried out using the statistical software IBM - SPSS version 21.0. (IBM Corp. Atlanta, GA).

\section{Ethical approval}

Ethical approval was sought and got from the research and ethics committee of the Federal Medical Centre in accordance with the Helsinki declaration. A prior consent was obtained from each of the participants.

\section{RESULTS}

A total of 105 participants were involved in the experiment with a total of 26 (24.76\%) males and 29(20.95\%) females diabetic while 19(18.10\%) males and 31(29.52\%) females were the non - diabetic control (Table 1). The highest number of ocular infection 29(27.62\%), was seen among female diabetics while the least occurrence of 22(20.95\%) was among the male non diabetic (control group) (Table 1). In the distribution of ocular infection in the study area, Conjunctivitis had the highest occurrence in the experimental and control groups; $21(38.2 \%)$ and $24(48.0 \%)$ respectively (Table 2). Corneal Ulcer 6(10.91\%) and $4(8.0 \%)$ in the experimental and control groups respectively, while blepharitis with $5(9.09 \%)$ and $6(12.0 \%)$ respectively were the least in frequency compared to other eye infections (Table 2). Staphylococcus aureus had 31 (56.4\%) and 28 (56.0\%) for the experimental and control groups respectively, which was the highest isolate found in both groups (Table 3). Coliforms and Bacillus spp. were 5(9.09\%) and 2(4.0\%) respectively. However, Corynebacterium diphtheria were 3(5.45\%) and 0(0.0\%), Pseudomonas aeruginosa 3(5.45\%) and 3(6.0\%), Staphylococcus albus 2(3.64\%) and 3(6.0\%) were isolated from the experimental and control groups respectively.

Table 1: Gender Distribution of Ocular Infection in the Study Area.

\begin{tabular}{|c|c|c|c|c|c|}
\hline \multirow[t]{2}{*}{ Eye Infection } & \multicolumn{2}{|c|}{ DIABETIC (\%) } & \multicolumn{3}{|c|}{ Non-DIABETIC (\%) } \\
\hline & Male & Female & Male & Female & Total \\
\hline Blepharitis & $2(1.90)$ & $3(2.86)$ & $3(2.86)$ & $3(2.86)$ & $11(10.48)$ \\
\hline Stye & $6(5.71)$ & $6(5.71)$ & $5(4.76)$ & $7(6.67)$ & $24(22.86)$ \\
\hline Conjuctivities & $9(8.57)$ & $12(11.43)$ & $10(9.52)$ & $14(13.33)$ & $45(42.86)$ \\
\hline Keratitis & $5(4.76)$ & $6(5.71)$ & $1(0.95)$ & $3(2.86)$ & $15(14.29)$ \\
\hline Corneal Ulcer & $4(3.81)$ & $2(1.90)$ & $3(2.86)$ & $1(0.95)$ & $10(9.52)$ \\
\hline Total & $26(24.76)$ & $29(27.62)$ & $22(20.95)$ & $28(26.71)$ & 105 \\
\hline
\end{tabular}

Key: $(\overline{\%})=$ Percentage

Table 2: Distribution of ocular infection in the study area

$\begin{array}{lll}\text { Type of Infection } & \text { Experimental Number (\%) } & \text { Control Number (\%) }\end{array}$

Www.scirj.org

(C) 2020, Scientific Research Journal 


\begin{tabular}{lll}
\hline Blepharitis & $5(9.09)$ & $6(12.0)$ \\
Conjunctivitis Stye & $21(38.18)$ & $24(48.0)$ \\
Corneal Ulcer & $12(21.82)$ & $12(24.0)$ \\
Keratitis & $6(10.91)$ & $4(8.0)$ \\
Total & $11(20.0)$ & $4(8.0)$ \\
& $\mathbf{5 5}(\mathbf{1 0 0})$ & $\mathbf{5 0}(\mathbf{1 0 0})$
\end{tabular}

\section{KEY: $(\%)=$ Percentage}

Table 3: $\quad$ Distribution of Microbes isolated from study participants

\begin{tabular}{lll}
\hline Type of Infection & Experimental Number $(\boldsymbol{\%})$ & Control Number $(\%)$ \\
\hline Staphylococcus aureus & $31(56.36)$ & $28(56.0)$ \\
Staphylococcus albus & $2(3.64)$ & $3(6.0)$ \\
Streptococcus pyogenes Coliform & $11(20.0)$ & $14(28.0)$ \\
bacillus Corynebacterium & $5(9.09)$ & $2(4.0)$ \\
diphtheria Pseudomonas & $3(5.45)$ & $0(0.0)$ \\
aeruginosa & $3(5.45)$ & $3(6.0)$ \\
Total & $\mathbf{5 5 ( 1 0 0 )}$ & $\mathbf{5 0}(\mathbf{1 0 0})$
\end{tabular}

KEY: $(\%)=$ Percentage

\section{DISCUSSION}

The major eye infections among the participants in this study comprised of conjunctivitis $21(38.18 \%)$ and stye $12(21.82 \%)$ in the experimental group and $24(48.2 \%)$ and $12(24.0 \%)$ in the control group respectively. This finding is in agreement with the findings of the second Dutch National Survey of General practice ${ }^{7}$, whose study showed conjunctivitis and stye as the common eye infections among diabetics attending a community eye centre. Keratitis $11(20.0 \%)$ and $4(8.0 \%)$ in the experimental and control groups respectively was another significant eye infection seen. This agrees with the finding in a study on the ocular health status of diabetics in Uyo, Akwa Ibom State ${ }^{15}$.

Staphylococcus aureus $31(56.36 \%$ ) in the experimental group and $28(56.0 \%)$ in the control group were the most common isolates in this study. This finding agrees with a study in Sierra - Leone ${ }^{16}$ which reported Staphylococcus aureus as the most common aerobic bacteria in eye infections among diabetics. Similarly, study carried out in Kashan, Iran, ${ }^{17}$ found Staphylococcus aureus as the most common organism constituting the normal flora of the conjunctiva. The second most common ocular microbe isolated was Streptococcus pyogenes 11(20.0\%) and 14(28.0\%) from the experimental and control groups respectively. It disagreement with study conducted in Karachi Pakistan ${ }^{18}$ that reported very high isolation of Streptococcus pyogenes from eye infections, especially stye among diabetics.

Statistically, there is no significant relationship between common ocular microbes and eye infections in diabetics in this study. This is shown in the correlation $r=-0.013$ at 0.927 level of significance which is greater than $0.05(r=-0.03$ at $0.927, \mathrm{P}>0.05)$.

Also statistically, from the coefficient table, the beta $(\beta)$ value is 0.430 with $t$ value at 3.297 with $\mathrm{p}$ value of 0.002 which is less than $0.05(\mathrm{c}=0.430, \mathrm{t}=3.297, \mathrm{p}(0.05)$, hence common ocular microbes in diabetic $\mathrm{s}$ with eye infections are the same in diabetics without eye infection.

From the ANOVA table, the t value was 10.873 and the $\mathrm{p}$ value was 0.002 which was less than 0.05 , this showed that common ocular microbes in diabetic participants were the same in non-diabetic participants. The findings in this study were in agreement with the study in Yozgat, Turkey ${ }^{19}$ and could be subjected to further study.

WWW.scirj.org 


\section{CONCLUSION}

Ocular microbes in diabetics with eye infection are the same in diabetics without eye infections. Staphylococcus aureus is a normal flora in the conjunctiva of the human eye and can become virulent when the ocular immunity is compromised. Most ocular infections can be caused by the normal flora of the eyes when host immunity is compromised. Hyperglycemia do not predispose diabetics to ocular infections.

\section{REFERENCES:}

1. A.A. Al-Ghadyan. Diabetic Retinopathy: An Update. Saudi J.Ophthalmol, 25; 99 - 111, 2011.

2. A.G. Pittas, A.S. Greenberg. Contemporary Diagnosis and Management of Diabetes. Handbooks in Health Care Co, Newton,PortAubury, 2003.

3. P.C. Clark - Far, M.M. Nel, A.C. Wilkinson. An Investigationinto diabetic patients knowledge of diabetes and its Ocular Complications in the Western Cape .S. Afr. Optom. 65; $134-143,2006$.

4. I. Ricci - Cabello, I. Ruiz - Perez, A. Rojas - Garcia, G. Pastor. Characteristics and Effectiveness of Diabetes Self-Management Educational Programs Targeted to Racial

/ Ethnic Minority Groups. A Systematic Review, Meta-analysis and Meta-regression. BMC Endocrine Disorders. 14; 60, 2014.

5. C. Deniz, O.O. Aliska, O. Esin, I. Aysun. Evaluation of Awareness of Diabetes Mellitus and Associated Factors in Four Health Centres Areas. Pat. Edu. Counsel. 62; 142 - 147, 2006. Retrieved on 31 July 2018, https://dx.doi.org/10.1016.j.pec.

6. S.E. Geerlings, A.I.M. Hoepelman, A.I.M, Jonker .C. (1999). Immune Dysfunction in Patients with Diabetes Mellitus. FEMS Immunology and Medical Microbiology. 26 (3-4); 259 - 265, 1999. Retrieved on 31 July 2018, https://doi.org/10.1111/j.1574- 695x.1999.+b01397.

7. L.M. Muller, K.J. Gorter, E. Hak, W.L. Goudzwaard, F.G. Schellevis, A.I. Hoepelman, G.E. Rutten. Increased Risk of Common Infections in Patients with Type 1 and Type 2 Diabetes Mellitus. Clin. Infect. Dis. 41 (3); 281 288, 2005.

8. M.R. Mookiah, U.R. Acharya, C.K. Chua. Computers in Biology and Medicine ( $2^{\text {nd }}$ ed.) Butterworth - Heinemann - Elsevier, 2013.

9. E. Chew. Comparing the Disease Profiles of Adult Patients with Type 2 Diabetes Mellitus attending four Public Health Facilities in Malaysia. Asia Pac J Public Health 25 (4); 316 - 325, 2013.

10. J.A. Carton, F. Perez - Gonzalez, V. Asensi. Diabetes Mellitus and Bacteramia: A comparative study between diabetic and non-diabetic patients. Eur. J. Med. 1;281-287, 1999.

11. N.S. Levitt. Diabetes in Africa Epidemiology, Management and Health Care Challenges. HEART. 94 (11); $1376-$ 1382, 2008. Retrieved on 31 July 2018, https://doi.10.1136/hrt.2008.147306.

12 E.C.C. Chukwunonso, K.U. Nnamdi, O.N. Stella. Diabetes and Pre-diabetes in Adult Nigerians: Prevalence, and Correlations of Blood Glucose Concentrations with Measures of Obesity. Afr. J. Bio. Res. 9 (3); 55 - 60, 2015.

13. J. Pearson-Studdard, S. Blundell, T. Harris, D.G. Cook, J. Critchley. Diabetes and Infection: assessing the association with glycaemic control in population-based studies. Lancet Diabetes Endocrinol. 4; 148 - 158, 2016.

14. S. Blundell. Diabetes, Level of Glycemic Control, and Eye Infections. J. Am. Ophthalmol. 5; 56 - 59, 2016.

15. E.G. Abraham, G. Emem, V. Umoh. Health Status of Diabetes Mellitus Patients in Uyo, South-South Nigeria. $S R$ J. Dent. and Med. Sci. 9; $24-26,2013$.

16. J.A.I Capriotti, J.S Pelletier, M. Shan, D.M. Caivano, D.C Ritterband. Normal Ocular Flora in Healthy Eyes from a Rural Population in Sierra - Leone. Int. Ophthamol. 29; 81 - 84, 2009.

17. A. Davood, K. Ahmad. Antibiotic Resistance Patterns of Ocular Surface Bacterial Flora. Iranian J. Clin. Infec. Dis. 2 (3); 133 - 137, 2007.

18. M.A. Tahir, Q. Saleem, I. Saeed, A.M. Manzoor. Aerobic Bacterial Conjunctival Flora in Diabetic Patients. Pak J. www.scirj.org (C) 2020, Scientific Research Journal http://dx.doi.org/10.31364/SCIRJ/v8.i10.2020.P1020818

This publication is licensed under Creative Commons Attribution CC BY. 
Ophthamol. 4; $177-181,2010$.

19. A. Mehmet, B. Mehmet, G. Canan. Conjunctival Flora in Diabetic and non-diabetic individual Turk. J. Ophthalmol. 45 (5) 193 - 196, 2015.

WwW.scirj.org

(C) 2020, Scientific Research Journal 